\title{
PENGEMBANGAN DAN EVALUASI PRODUCT SERVICE SYSTEM (PSS) PADA PERUSAHAAN FURNITUR MENGGUNAKAN METODE MULTI- LAYER QFD
}

\author{
Fatma Ayu Nuning Farida Afiatna \\ Teknik Industri, Fakultas Teknik Industri, Universitas Hasyim As'ary \\ fatmaayu2511@gmail.com
}

Anityasari,M

Teknik Industri, Fakultas Teknik Industri, Institut Teknologi Sepuluh Nopember Surabaya m_anityasari@yahoo.com.au

\section{Surjani,R.M}

Teknik Industri, Fakultas Teknik Industri, Universitas Hasyim As'ary rositameitha@yahoo.com

\begin{abstract}
Perkembangan usaha bisnis berjalan cukup dinamis dan berimplikasi terhadap kompetisi antar perusahaan. Orientasi penyediaan produk saja mungkin tidak bisa mempertahankan daya saing perusahaan dalam jangka panjang. Sustainability menjadi perhatian yang sangat penting bagi perusahaan. Product Service System (PSS) sebagai strategi bisnis memiliki potensi besar untuk memberikan solusi bagi perusahaan sekaligus menjawab kebutuhan konsumen melalui integrasi produk dan servis. Furnitur sebagai hasil produksi industri merupakan kebutuhan dan disukai oleh kalangan masyarakat urban. Perusahaan furnitur berkompetisi untuk mengembangkan produk dan servis untuk memenuhi kebutuhan konsumen. PSS menawarkan strategi yang dapat memberikan sustainability dalam dunia usaha yang kompetitif. Di Indonesia masih sangat sedikit penelitian mengenai strategi yang ditawarkan oleh PSS dengan mempertimbangkan kebutuhan segmentasi konsumen dan perusahaan. Pada penelitian ini akan dikaji kepentingan konsumen dan perusahaan dalam pengembangan PSS furnitur dengan metode Multi-layer QFD dan Fuzzy-AHP. Dari preferensi konsumen dan perusahaan selanjutnya akan dilakukan desain PSS berdasarkan HoQ dari Multi-layer QFD yang dapat direkomendasikan sebagai program untuk meningkatkan daya saing perusahaan. Pengembangan desain PSS furnitur akan menganalisis model bisnis PSS Product-oriented Services dan Use-oriented Services yang dituangkan dalam PSS Blueprint. Selanjutnya evaluasi PSS berdasarkan sudut pandang konsumen dan perusahaan dilakukan untuk mengevaluasi desain PSS.
\end{abstract}

Abstrak

Kata Kunci: Pengembangan PSS, Evaluasi PSS, Model PSS, PSS Blueprint, Multi-layer QFD, FuzzyAHP
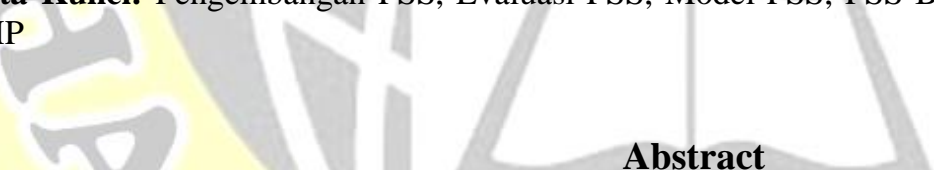

\section{Abstract}

The business development runs quite dynamic and affects the competition among companies. Providing physical product alone is not sufficient to maintain the company's competitiveness in the long run. Sustainability issue becomes a very important concern for the company. Product Service Systems (PSS) is a business strategy that has great potential benefit to provide solutions for companies in addressing the customer needs through the integration of products and services. As one of industrial products, furniture is demanded and favored by the urban community. Furniture companies competes each other to develop products and services to meet customer needs. PSS offers strategies that can provide sustainability in a competitive business world. In Indonesia, there is limited research on PSS strategies by considering the need of customers and providers segmentation. This research will investigate the interests of customers and provider in developing PSS furniture by using Multi-layer Quality Function Deployment methodology and Fuzzy-AHP. The development of PSS for furniture company will analyze the business model of Productoriented Services and Use-oriented Services as revealed in PSS Blueprint. Furthermore, the evaluation of PSS design is performed based on the perspective of customers and provider.

Keywords: PSS development, Fuzzy-AHP, Multi-layer QFD, PSS Blueprint, PSS evaluation 


\section{PENDAHULUAN}

Permasalahan pembangunan berkelanjutan saat ini menjadi isu Internasional yang menarik perhatian sekaligus tanggung jawab banyak pihak. Pembangunan berkelanjutan adalah pembangunan yang memenuhi kebutuhan saat ini tanpa mengorbankan kemampuan generasi mendatang dalam memenuhi kebutuhan mereka sendiri. Kajian mengenai pembangunan berkelanjutan menjadi perhatian banyak pihak. Sampai saat ini, kajian pembangunan berkelanjutan dalam dunia industri masih sering membahas mengenai penurunan emisi. Di sisi lain, pembangunan berkelanjutan bisa dilakukan melalui efisiensi sumber daya, orientasi pengembangan teknologi, dan mengubah pola konsumsi menjadi lebih baik.

Perkembangan usaha bisnis berjalan cukup dinamis dan berimplikasi terhadap kompetisi dalam industri manufaktur. Daya saing melewati masa transisi yang cepat, orientasi penyediaan produk saja mungkin tidak bisa mempertahankan daya saing perusahaan dalam jangka panjang (Kim dkk, 2012:1). Product Service Sistem (PSS) sebagai strategi bisnis memiliki potensi besar untuk memberikan solusi bagi industri sekaligus menjawab kebutuhan konsumen melalui integrasi produk dan servis. PSS memberikan pembaharuan struktur dalam pelayanan untuk memfasilitasi produksi dan konsumsi yang berkelanjutan (Tukker dkk, 2006:2) serta memberikan dampak yang signifikan terhadap pengurangan penggunaan sumber daya (Clark dkk, 2009:3).

Potensi manfaat yang ditawarkan oleh PSS memberikan solusi terpadu yang berdampak pada aspek lingkungan, sosial, dan ekonomi, dimana perusahaan dapat mengoptimalkan pemanfaatan sumber daya dan peningkatan daya saing (Boehm dkk, 2013:4). Para peneliti juga telah mengembangkan metodologi untuk mendesain PSS (Morelli, 2006:5). Pada tahap desain dan integrasi PSS desainer membuat desain konsep secara detail dan integrasi antar stakeholders yang terlibat. Hubungan antar stakeholders tersebut secara rinci dijelaskan dalam PSS blueprint (Geum dkk, 2011:6). Namun demikian penelitian-penelitian tersebut belum mempertimbangkan multi-dimentional aspect seperti multi actor yang terlibat dalam PSS. Sesungguhnya multi actor seperti konsumen dan provider penting untuk dipertimbangkan dalam pengembangan dan keberhasilan PSS. Di lain pihak, peneliti Duru et al. (Duru dkk, 2013:7) berhasil membuat pendekatan yang terintegrasi dalam mengembangkan servis. Duru et al. (Duru dkk, 2013:7) menggunakan metode Fuzzy-AHP untuk mengolah data dan mengembangkan konsep Multi-layer QFD dalam perencanaan pengembangan servis dengan mempertimbangkan multi actor. Penelitian tersebut mempertimbangkan kebutuhan konsumen dan provider dalam pengembangan servis. Namun, Duru et al. (Duru dkk, 2013:7) tidak mempertimbangkan strategi PSS. Surjani et al. (Surjani dkk, 2015:8) mengadopsi Multilayer QFD untuk pengembangan PSS dengan memperhatikan kebutuhan dari multi actor.

Besch melakukan penelitian mengenai tantangan dan peluang PSS untuk office furniture dan menyarankan agar melakukan pendekatan untuk mengetahui kriteria produk dan menseleksi produk agar bisa sukses dalam menjalankan PSS sehingga bisa digunakan sebagai pedoman bagi perusahaan furnitur untuk mengembangkan PSS (Besch, 2004:9). Perdagangan furnitur secara global telah berkembang pesat dalam dekade terakhir, hal tersebut ditunjang dari inovasi dalam pendistribusian serta packaging produk yang siap-rakit/knock-down sehingga memudahkan perdagangan antar dunia (Lee dkk, 2015:10). Di sisi lain, akibat dari perkembangan furnitur ada kekhawatiran tentang dampak lingkungan yang berasal dari produksi dan timbul pertanyaan bagaimana siklus hidup furnitur (Garcia dkk, 2011:11). Oleh karena itu, desain PSS untuk furniture perlu untuk dikaji.

Keberhasilan PSS tidak hanya ditentukan pada proses desain PSS. Evaluasi desain PSS memiliki peran yang sangat penting untuk mendukung keberhasilan PSS. Yoon et al. (2012) mengembangkan sebuah model evaluasi berdasarkan sudut pandang konsumen dan provider. Lee et al. (2015) mengevaluasi pengembangan PSS berdasarkan customer value dan customer experience cycle. Berdasarkan latar belakang yang telah dijelaskan di atas, maka pada penelitian ini akan dilakukan analisis terhadap multi actor untuk mendapatkan kepentingan konsumen dan perusahaan dengan menggunakan FuzzyAHP yang kemudian dilakukan pengembangan bisnis model PSS untuk furnitur berdasarkan analisis dari Multilayer QFD dan evaluasi desain PSS

\section{METODE}

A. Pengembangan PSS

Product Service System (PSS) dapat didefinisikan sebagai sebuah sistem yang mengintegrasikan produk dan servis untuk memenuhi kebutuhan konsumen Gaedkoop M, v. H (1999). Secara umum PSS diklasifikasikan menjadi 3 kategori, yaitu Product-oriented, Use-oriented, dan Result-oriented. Pada kategori Product-oriented (Po) PSS, sistem berorientasi menjual produk serta komitmen untuk memberikan layanan yang terkait dengan produk. Pada Use-oriented (Uo) PSS, provider tidak berorientasi menjual produk fisik namun konsumen dapat menggunakan fungsi produk tersebut, sistem dapat tersedia dalam bentuk layanan dan dimungkinkan untuk dipakai bersamaan dengan beberapa pengguna. Pada Result oriented (Ro) PSS, provider menyediakan produk 
atau servis yang diperlukan konsumen namun tidak ada produk atau servis yang terlibat langsung, hanya terbatas kesepakatan antara klien dan provider menurut A.Tukker (2004). Eight types of producteservice system: eight w. Dalam penelitian ini pengembangan PSS furnitur akan menganalisis Product-oriented PSS dan Use-oriented PSS. Untuk Use-oriented PSS akan dilakukan analisis terhadap penyewaan furnitur. Hal tersebut dikarenakan strategi Result-oriented Services tidak sesuai dalam studi kasus yang dikembangkan.

Secara umum, pengembangan PSS terdiri dari tujuh tahap yaitu pengembangan ide PSS, perencanaan PSS, analisis permintaan, desain dan integrasi PSS, evaluasi, implementasi, dan retirement dan recycling Tuan \& Joon (2014). Pengembangan PSS secara sistematis dijelaskan pada Gambar 1. Pada tahap pengembangan ide PSS, seorang desainer PSS perlu menganalisis lingkungan internal dan eksternal perusahaan yang melingkupi peluang pasar, bisnis model PSS, kategori PSS yang akan dikembangkan, dan ide PSS. Pada tahap perencanaan PSS seorang desainer perlu merencanakan alokasi sumber daya, segmentasi pasar, dan penjadwalan PSS. Pada tahap analisis permintaan konsumen desainer perlu mengidentifikasi kebutuhan pelanggan, benchmarking, dan spesifikasi PSS. Pemahaman yang jelas tentang kebutuhan konsumen sangat penting.

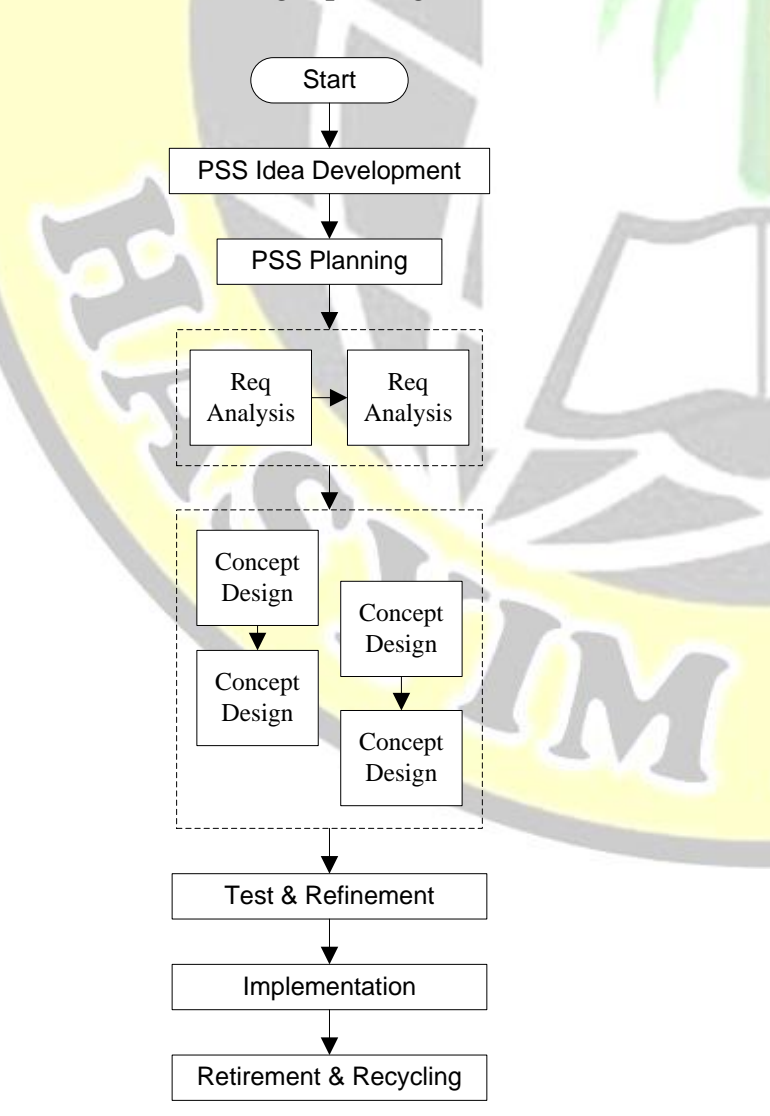

Gambar 1. Pengembangan PSS secara sistematis Source: Tuan \& Joon (2014)
Kim et al (2012) memberikan sebuah skema referensi model PSS yang dapat membantu desainer PSS dalam memecahkan kebutuhan konsumen secara umum. Kim et al (2012) berhasil mengidentifikasi general need untuk konsumen yang diuraikan pada Tabel 1 dan layanan yang bisa dikembangkan untuk pengembangan PSS pada Tabel 2. Pada tahap desain dan integrasi PSS desainer membuat desain konsep secara detail dan integrasi antar stakeholders yang terlibat. Hubungan antar stakeholders tersebut secara rinci dijelaskan dalam PSS blueprint (Geum \& Park, 2011). PSS blueprint didefinisikan sebagai peta yang menggambarkan sistem produk dan servis yang terpadu dan sistematis untuk memberikan peningkatan value dan sustainability. Dalam PSS blueprint dijelaskan bahwa PSS terdiri dari tiga area utama yaitu area produk, area servis, dan area pendukung seperti ditunjukkan dalam Gambar 2. Evaluasi PSS bisa diperoleh dari uji implementasi atau feedback dari konsumen.Selanjutnya pengembangan PSS bisa terus dilakukan melalui retirement dan recycling pada end of life PSS.

\section{B. MULTI-LAYER QFD}

Penelitian pengembangan produk yang memperhatikan kepuasan konsumen dan provider telah diteliti dalam model Multi-layer QFD (Duru, 2013). Multi-layer $Q F D$ dimodelkan dalam bentuk tiga dimensi yang menggambarkan HoQ (House of Quality) dari konsumen, HoQ dari provider, dan cross-synthesis dari konsumen dan provider. Gambar 3 menggambarkan struktur Multi-layer $Q F D$. Permukaan anterior kubus menunjukkan matriks HoQ orisinil yang beroientasi dari kepuasan dan kebutuhan konsumen dengan multi segment. Di sisi kanan kubus menunjukkan matriks HoQ yang berorientasi terhadap kepuasan/kebutuhan provider. Persyaratan kepuasan/kebutuhan provider bersifat berbeda, dimana persyaratan kepuasan/kebutuhan konsumen ditunjukkan oleh edge\#1 sedangkan kepuasan/kebutuhan provider ditunjukkan edge\#2. Selanjutnya technical response diperoleh dari kedua matriks yang identik (edge\#3). Bagian atas kubus menunjukkan matriks cross-synthesis untuk conflict resolution. Ukuran matriks cross-synthesis didasarkan pada permintaan kedua elemen (provider dan konsumen). Multi-layer QFD digunakan untuk menyelidiki hubungan antara preferensi kebutuhan konsumen dan provider.

Tingkat kepentingan kriteria permintaan didefinisikan melalui penilaian prioritas dengan menggunakan metode Fuzzy-AHP. Kemudian hasil dari tingkat kepentingan relatif masing-masing kriteria akan dihitung satu dengan yang lain. Penyelesaian analisis cross-synthesis diakhiri dengan melakukan sintesis ratarata dari kriteria kepentingan relatif dari masing-masing actor. 


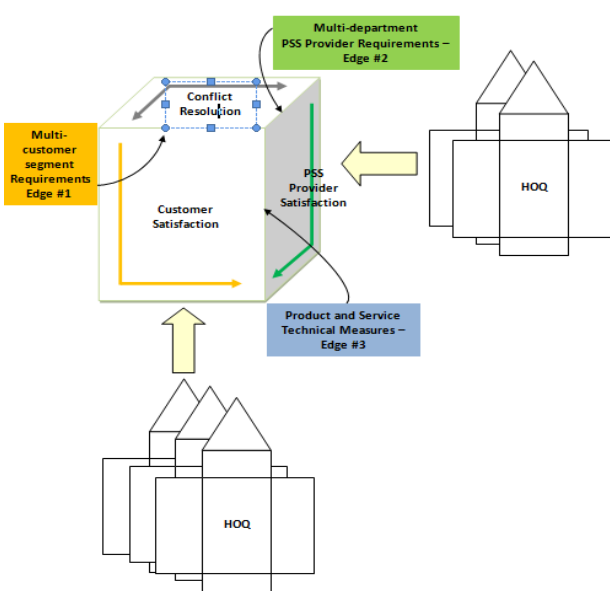

Gambar 3. QFD Multy layer dengan multi segment Source : Surjani et al.[8]

C. Evaluasi PSS

Untuk mencapai keberhasilan PSS evaluasi PSS harus dipertimbangkan. Evaluasi PSS harus mempertimbangkan sudut pandang dari provider dan konsumen [9]. Evaluasi dari sudut pandang provider berkenaan dengan potensi resiko saat PSS yang dirancang mengkonfirmasikan peluang keberhasilan yang tinggi. Evaluasi dari sudut pandang konsumen mengacu terhadap tanggapan dan pikiran calon konsumen. Pada Tabel 3 dijelaskan kriteria dari provider dan konsumen.

Tabel 3 Kriteria Evaluasi.

\begin{tabular}{l|ll}
\hline Variabel & \multicolumn{1}{|c}{ Kriteria } & \multicolumn{1}{c}{ Sumber } \\
\hline Provider & Ekonomi & Yoon et al, 2012 \\
need & Teknologi & Yoon et al, 2012 \\
Customer & Efisiensi Biaya & Lee at al, 2015 \\
need & Efisiensi waktu & Lee at al, 2015 \\
& Pelayanan & Mert at al, 2014 \\
\hline
\end{tabular}

\section{HASIL DAN PEMBAHASAN}

Penilaian tingkat kepentingan kebutuhan konsumen untuk furnitur dan preferensi konsumen terhadap layanan berdasarkan segmentasi konsumen diperoleh dari survey, Berdasarkan penilaian kepentingan kriteria general need dari multi actor yang terlibat dalam ruang lingkup penelitian dan penilaian tingkat kepentingan provider diperoleh dari CEO/expert (dari penilaian kepentingan berdasarkan Tabel 1 dan Tabel 2) diperoleh kriteria terpilih dari perhitungan Fuzzy-AHP. Selanjutnya dilakukan analisis Cross-synthesis dan dibentuk HoQ Multi-layer QFD masing-masing actor.

Dari hasil analisis sebelumya akan menghasilkan HoQ Multi-layer QFD yang selanjutnya digunakan sebagai input dalam desain PSS. Matriks sintesis konsumen dan provider digunakan untuk mengidentifikasi kriteria produk dan servis yang akan dikembangkan. Selanjutnya dilakukan identifikasi model PSS dan generalisasi konsep PSS yang sesuai dengan kebutuhan konsumen dan provider. Dari konsep desain yang terbentuk selanjutnya dibangun PSS blueprint berdasarkan model PSS yang sesuai dengan kebutuhan konsumen dan provider. PSS blueprint untuk Product-oriented PSS dan Use-Oriented PSS dijelaskan pada gambar 9 dan 10.
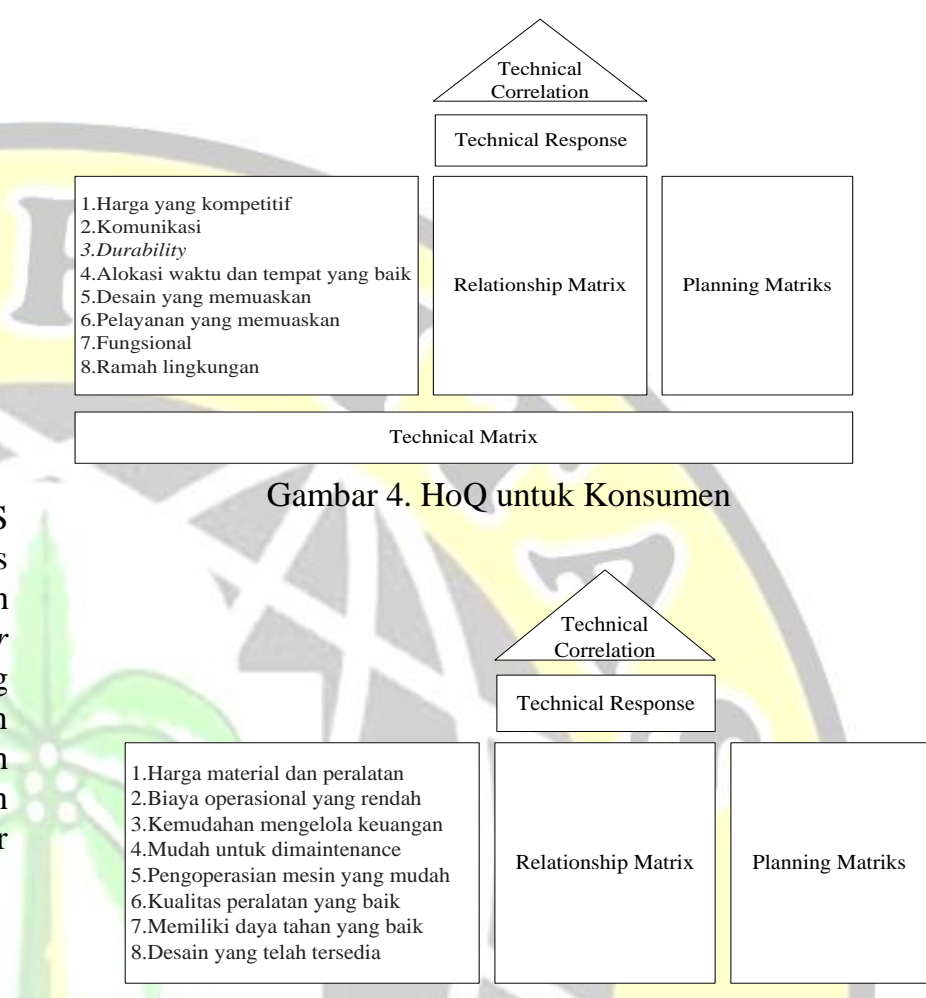

Technical Matrix

Gambar 5. HoQ untuk Provider

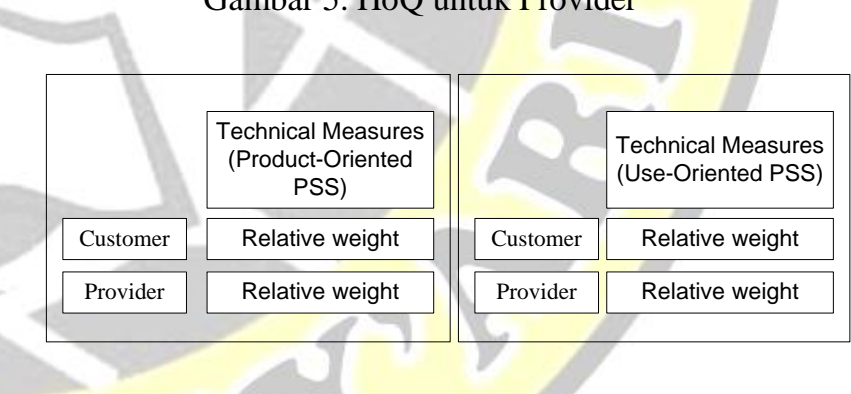

Gambar 6. Design selection objectives for Product-

Oriented and Use-Oriented PSS

Evaluasi berdasarkan sudut pandang provider antara lain berkaitan dengan kelayakan ekonomi dinilai berdasarkan biaya investasi, market size, dan growth analysis. Kelayakan teknologi dinilai berdasarkan kemampuan perusahaan untuk memecahkan masalah operasional. Evaluasi berdasarkan sudut pandang konsumen yaitu berkaitan dengan kemampuan untuk mendapatkan produk/servis dengan biaya yang efisien, kemampuan untuk mendapatkan produk/servis dengan waktu yang efisien, dan Standard operation procedures (SOP) untuk mendapatkan produk dan servis. 


\section{PENUTUP}

Penelitian ini mendapatkan kriteria kepentingan konsumen dan perusahaan dalam pengembangan PSS furnitur dengan metode Multi-layer QFD dan Fuzzy-AHP. Desain strategi PSS berdasarkan HoQ dari Multi-layer QFD yang dapat direkomendasikan sebagai program untuk meningkatkan daya saing perusahaan furnitur. Evaluasi desain strategi PSS pada perusahaan furnitur berdasarkan sudut pandang konsumen dan provider. Konsep PSS menawarkan potensi yang bisa memberikan perubahan dalam pola produksi dan konsumsi yang berimplikasi terhadap sustainability, manfaat praktis dapat ditujukan kepada perusahaan, konsumen, dan lingkungan. Pengembangan dan evaluasi PSS dapat dibuat sebagai acuan dalam pembuatan model business development. Analisis yang dilakukan dapat membantu untuk memberikan pertimbangan terhadap pengimplementasian PSS yang diharapkan dapat membuka kesempatan dalam melakukan strategi untuk meningkatkan daya saing perusahaan yang berimplikasi terhadap keuntungan perusahaan.

\section{DAFTAR PUSTAKA}

Kim, K.-J., Lim, C.-H., Lee, D.-h., Lee, j., Hong, Y.-S., \& Park, K. (2012). A Concept Generation Support System for Product-Service System Development. Service Science, 349-364.

Tukker, A., \& Tischner, U. (2006). Product services as a research field: past, present and future. Journal

Cleaner Production 14 (17), 1552-1556.

Clark, G., Kosoris, J., Hong, L., \& Crul, M. (2009). Design for sustainability: current trends in sustainable product design and development. Sustainability 1 (3), 409-424.

Boehm, M., \& Thomas, O. (2013). Looking beyond the rim of one's teacup: a multi-disciplinary literature review of product service system in information systems, business management, and engineering \& design . Journal Cleaner Production 51, 245-260.

Morelli, N. (2006). Developing new product service systems (PSS): methodologies and operational tools. Journal Clean Production 14, 1495-1501.

Geum, Y., \& Park, Y. (2011). Designing the sustainable product service integration: a product service blueprint approach. Journal of Cleaner Production 19, 1601-1614.

Duru, O., Huang, S. T., Bulut, E., \& Yoshida, S. (2013). Multy-layer quality functional deployment (QFD) approach for improving the compromised quality satisfaction under the agency problem: A $3 D Q F D$ design for the asset selection problem in the shipping industry. Springer.

Surjani, R. M., Ciptomulyono, U., \& Anityasari, M. (2015). Collaborative Design of Product-service systemwith Multi-Segment: Framework and Model.
International Conference on Advance Science and Technology (ICAST)..

Besch, K. (2004). Product-service systems for office furniture: barriers and opportunities on the European market. Journal of Cleaner Production, 1083-1094.

Lee, S., Geum, Y., Lee, S., \& Park, Y. (2015). Evaluating new concept of PSS based on the customer value:Application of ANP and niche theory. Expert Systems with Applications 42, 4556-4566.

García, S. G., Gasol, C. M., Lozano, R. G., Moreira, M. T., Gabarrell, X., Pons, R. i., et al. (2011). Assessing the global warming potential of wooden products from the furniture sector to improve their ecodesign. Science of the Total Environment 410-411, 16-25.

Yoon, B., Kim, S., \& Rhee, J. (2012). An evaluation method for designing a new product-service system. Expert Systems with Applications 39, 3100-3108.

Han, X., Wen, Y., \& Kant, S. (2009). The global competitiveness of the Chinese wooden furniture industry. Forest Policy and Economics 11, 561-569.

Gaedkoop M, v. H. (1999). Product service systems, ecological and economic basis. The report No.1999/36, 22-5.

Tukker, A. (2004). Eight types of producteservice system: eight ways to sustainability? Experiences from SusProNet. Business Strategy Environment 13 (4), 246-260.

Tuan A, T., \& Joon Y, P. (2014). Development of integrated design methodology for various types of product - service systems. Journal of Computational Design and Engineering, Vol. 1, No. 1, 37 47. 